D:INsurg|Vol. 23, No. 4, Oct. - Dec., 2019\Nsurg-12.Doc $\quad$ (A) $\quad$ P. $283-287 \quad$ IV

ORIGINAL ARTICLE

\title{
Clinical Outcome of Percutaneous Radiofrequency Rhizotomy for Trigeminal Neuralgia at a Tertiary Care Hospital
}

\author{
MUHAMMAD HASSAN RAZA, ADEEB-UL-HASSAN \\ OMAIR AFZAL ALI, KHALID MAHMOOD
}

Punjab Institute of Neurosciences (PINS), Lahore General Hospital, Lahore - Pakistan

DOI: https://doi.org/10.36552/pjns.v23i4.373

\begin{abstract}
Background: Trigeminal neuralgia is a syndrome typicallyconsidered by involuntarypain in the distribution of Fifth nerve that are activated by non-noxious stimuli. Medical Treatment with anticonvulsant remained the 1st line of treatment. ${ }^{3}$ If the disease becomes non responsive, there are numerous surgical options like MVD or minimally invasive percutaneous lesioning of the trigeminal nerve, such as glycerol rhizolysis, Balloon Compression, Radiofrequency Rhizotomy.
\end{abstract}

Objective: To determine efficacy of percutaneous Radiofrequency Rhizotomy for trigeminal neuralgia in terms of early pain relief in a tertiary care hospital.

Materials and Methods: 62 patients with refractory trigeminal neuralgia or lancinating, recurrent episodes of pain in the distribution ofOphthalmic (V1) andMandibular (V3) branches of the trigeminal nerve, not responsive to 6 months of conservative treatment were included.

Result: In our study population, 62 included patients were had mean age $56.08 \pm 7.39$ years. 44 patients $(71 \%)$ were male. Our treatment was effective in 58 patients (93.5\%), while there was recurrence among 4 (6.5\%) only.

Conclusion: It is concluded that the efficacy of percutaneous Radiofrequency Rhizotomy for trigeminal neuralgia in terms of complete relief of pain with intact sensations in treated branch region is excellent (93.5\%).

Keywords: Percutaneous Radiofrequency Rhizotomy, Trigeminal neuralgia efficacy, Mandibular Branch V3, Ophthalmic division of fifth nerve.

\section{INTRODUCTION}

TGNis a syndrome considered by involuntary facial pain. It is one of the most painful and debilitating craniofacial pain disorders. ${ }^{1}$ The occurrence of trigeminal neuralgia is estimated at 12.6 per 100,000 person-years. Women are more frequently affected than men, in a ratio about $2.5: 1 .^{2}$ Refractory trigeminal neuralgia is a lifelong disease affecting quality of life adversely.Though all surgical procedures allow pain relief in trigeminal neuralgia, from acost-effective point of view, percutaneous techniques of radiofrequency Rhizotomy are more cost-effective. ${ }^{8}$

Radiofrequency Rhizotomy is currently in use in our setup as it costs a patient minimal and complication rate is low as compared with other surgical interventions, but there has been no systematic observation for its efficacy locally.

Trends for intervention are changing all over the world. ${ }^{9}$ The recent advances and evidences are using CT guided approach ${ }^{5,7}$ which is not possible in our circumstances. So, current study will help audit the current practices in our hospitals against the standard outcome achieved elsewhere as there is no local data available to determine the outcome of Radiofrequency Rhizotomy in terms of early pain relief. If the disease becomes medically refractory, there are numerous surgical options like MVD or minimally invasive percutaneous lesioning of the trigeminal nerve, such as 
Balloon Compression Radiofrequency Rhizotomy, glycerol rhizolysis. ${ }^{3-5}$

\section{MATERIALS AND METHODS}

\section{Study Design}

Prospective study.

\section{Inclusion Criteria}

Sixty two patients with refractory trigeminal neuralgia or lancinating, recurrent episodes of pain in the distribution of Ophthalmic (V1) and Mandibular (V3) branches of the trigeminal nerve, not responsive to 6 months of conservative treatment were included after taking written consent from the patient and after the approval from the ethical committee of the hospital. Study was completed in one year i.e., from March 2015 to Feb 2016.

\section{Exclusion Criteria}

Recurrent cases.

\section{Data Collection}

Data was entered in specially designed performa.

\section{Data Analysis}

By SPSS Version 20.

\section{RESULTS}

\section{Age Incidence}

In our study population, 62 patients were included with a mean age of $56.08 \pm 7.398$ ranged from 43 to 67 years .44 patients $(71 \%)$ in our study population, were under 60 years of age whereas, 18 patients $(29 \%)$ were either 60 years or more in age (Table 1$)$.

Table 1: Frequency Distribution of sampled population by Age Groups.

\begin{tabular}{|c|l|c|c|}
\hline \multicolumn{2}{|c|}{} & Frequency & Percent \\
\hline \multirow{4}{*}{ Valid } & Less than 60 Years & 44 & 71.0 \\
\cline { 2 - 4 } & 60 Years and more & 18 & 29.0 \\
\cline { 2 - 4 } & Total & 62 & 100.0 \\
\hline
\end{tabular}

\section{Gender Distribution}

Forty four patients $(71 \%)$ were male and remaining 18 (29\%) were female.

Table 2: Frequency Distribution of sampled population by Time since Diagnosis > 1 Year.

\begin{tabular}{|c|l|c|c|}
\hline \multicolumn{2}{|c|}{} & Frequency & Percent \\
\hline \multirow{4}{*}{ Valid } & Less than 5 Years & 33 & 53.2 \\
\cline { 2 - 4 } & 5 Years and more & 29 & 46.8 \\
\cline { 2 - 4 } & Total & 62 & 100.0 \\
\hline
\end{tabular}

\section{Clinical Presentation}

Thirty three patients $(53.2 \%)$ of study population has been diagnosed in less than 5 years whereas in 29 patients $(46.8 \%)$, it was more than 5 years (Table 2). Branch V3 (mandibular) was involved in 50 patients (80.6\%) $12(19.4 \%)$ patients had involvement of ophthalmic division of trigeminal nerve (Table 3 ).

Table 3: Frequency Distribution of sampled population by Branch Involved.

\begin{tabular}{|c|l|c|c|}
\hline \multicolumn{2}{|c|}{} & Frequency & Percent \\
\hline \multirow{4}{*}{ Valid } & V3 & 50 & 80.6 \\
\cline { 2 - 4 } & V1 & 12 & 19.4 \\
\cline { 2 - 4 } & Total & 62 & 100.0 \\
\hline
\end{tabular}

Our treatment was effective in 58 patients $(93.5 \%)$ while, there was a recurrence among $4(6.5 \%)$ only (Table 4). When we cross tabulated age group with efficacy, 41 patients with positive efficacy were less than 60 years of age and remaining 17 with positive were either 60 years of age or more. When we applied

Table 4: Frequency Distribution of sampled population by Efficacy

\begin{tabular}{|c|l|c|c|}
\hline \multicolumn{2}{|c|}{} & Frequency & Percent \\
\hline \multirow{4}{*}{ Valid } & No & 4 & 6.5 \\
\cline { 2 - 4 } & Yes & 58 & 93.5 \\
\cline { 2 - 4 } & Total & 62 & 100.0 \\
\hline
\end{tabular}


fisher exact test results were non-significant $(\mathrm{p}=$ 0.854) (Table 5).

When time of diagnosis was cross tabulated with efficacy, using fisher's exact test, results were nonsignificant $(\mathrm{p}=0.116)$ (Table 6).

\section{DISCUSSION}

Although all surgical procedures allow pain relief in trigeminal neuralgia, from a cost-effective point of view, percutaneous techniques of radiofrequency Rhizotomyare more cost-effective. ${ }^{8}$ Radiofrequency Rhizotomy is currently in use in our setup as it costs a patient minimal and complication rate is low as compared with other surgical procedure but there has been no systematic observation for its efficacy locally. In our study, our treatment was effective in 58 patients $(93.5 \%)$ while, there was a recurrence among $4(6.5 \%)$ only in terms of complete relief of pain with intact sensations in treated branch region.

In a descriptive case series, the surgical result of CT-guided trigeminal Rhizotomycame out better in 63 of the 79 (80\%) patients with more than $90 \%$ (95\% CI $87.5-93.7 \%$ ) pain relief. ${ }^{6}$ While, another review study, it has been concluded that radiofrequency Rhizotomy allows for somatotropic nerve mapping, selective division lesioning, and provides pain relief in up to $97 \%$ of patients (needle not mentioned). ${ }^{7}$ Our results matched with CT guided Rhizotomy study conducted in Department of Neurosurgery, Chang Gung Memorial Hospital, Taiwan 2010, which mentioned that the surgical result of CT-guided trigeminal Rhizotomy using straight needle came out good in 63 of the $79(80 \%)$ patients with more than $90 \%$ pain relief with an incredible outcome in pain relief. $^{6}$

Our study results are comparable with another study related to the review of percutaneous treatments for trigeminal Neuralgia, which concluded that radiofrequency Rhizotomy allows for somatotropic nerve mapping, selective division lesioning, and provides pain relief in up to $97 \%$ of patients RFR provide effective pain relief in most of the patients.7 The difference in results may be secondary to inclusion of all patients of trigeminal neuralgia (maxillary division also) as the needle used was not mentioned. ${ }^{7}$ There was no effect of age, gender of
Table 5: Cross tabulation between Age groups \& Efficacy.

\begin{tabular}{|c|c|c|c|c|}
\hline & \multicolumn{2}{|c|}{ Efficacy } & \multirow{2}{*}{ Total } \\
\hline & & No & Yes & \\
\hline \multirow{2}{*}{$\begin{array}{l}\text { Age } \\
\text { groups }\end{array}$} & Less than 60 Years & 3 & 41 & 44 \\
\hline & 60 Years and more & 1 & 17 & 18 \\
\hline \multicolumn{2}{|r|}{ Total } & 4 & 58 & 62 \\
\hline
\end{tabular}

Table 6: Cross tabulation between Time since Diagnosis > 1 Year \& Efficacy.

\begin{tabular}{|c|c|c|c|c|}
\hline & \multicolumn{2}{|c|}{ Efficacy } & \multirow{2}{*}{ Total } \\
\hline & & No & Yes & \\
\hline \multirow{2}{*}{$\begin{array}{l}\text { Time since } \\
\text { Diagnosis }>1 \text { Year }\end{array}$} & Less than 5 Years & 4 & 29 & 33 \\
\hline & 5 Years and more & 0 & 29 & 29 \\
\hline \multicolumn{2}{|c|}{ Total } & 4 & 58 & 62 \\
\hline
\end{tabular}

patient, diabetes and time elapsed since diagnosis on efficacy in sampled population.

\section{CONCLUSION}

It is concluded that the efficacy of percutaneous radiofrequency Rhizotomy for trigeminal neuralgia in terms of complete relief of pain with intact sensations in treated branch region is excellent at current sample size. As in our study, $93.5 \%$ patients showed efficacy in terms complete relief of pain with intact sensations in treated branch region. There was no effect of age, gender of patient, diabetes and time elapsed since diagnosis on efficacy in sampled population.

\section{Limitation}

The current study included non-representative sample and non-probability sampling technique.It is a single centered study and a randomized controlled trial is needed for more comprehensive results.

\section{REFERENCES}

1. Shakur SF, Bhansali A, Mian AY, Rosseau GL. 
Neurosurgical Treatment of Trigeminal Neuralgia. Dis Mon. 2011; 57: 570-82.

2. Koopman JS, Dieleman JP, Huygen FJ. Incidence of facial pain in the general population. Pain, 2009; 147: 122-7.

3. Tatli M, Satici O, Kanpolat Y, Sindou M. Various surgical modalities for trigeminal neuralgia: literature study of respective long-term outcomes. Acta Neurochir. 2008; 150: 243-55.

4. Toda K. Operative treatment of trigeminal neuralgia: review of current techniques. Oral Surg Oral Med Oral Pathol Oral Radiol Endod. 2008; 106: 788-805.

5. Meng FG, Wu CY, Liu YG, Liu L. Virtual reality imaging technique in percutaneous radiofrequency rhizotomy for intractable trigeminal neuralgia. J Clin Neurosci. 2009; 16: 449-51.

6. Yang T, Lin M, Lee M, Weng H, Liao H. Percutaneous Trigeminal Nerve Radiofrequency Rhizotomy Guided by Computerized Tomography with Three-dimensional Image Reconstruction. Chang Gung Med J. 2010; 33: 679-83.

7. Cheng JS, Lim DA, Chang EF, Barbaro NM. A Review of Percutaneous Treatments for Trigeminal Neuralgia. Neurosurgery, 2013; 23:

8. Fransen P. Cost-effectiveness in the surgical treatments for trigeminal neuralgia. Acta Neurol Belg. 2012; 112 (3): 245-7.

9. Wang DD, Ouyang D, Englot DJ, Rolston JD, Molinaro AM, Ward M, et al. Trends in surgical treatment for trigeminal neuralgia in the United States of America from 1988 to 2008. J Clin Neurosci. 2013; Available at http://dx.doi.org/10.1016/j.jocn.2012.12.026-32.

10. Harden RN. Chronic neuropathic pain. Mechanisms, diagnosis, and treatment. Neurologist, 2005; 11: 111-6.

11. Bruyn GW. Nervus intermedius neuralgia (Hunt). Cephalalgia. 1984; 4: 71-5.

12. Goodwin, JG, Bajwa, ZH. Understanding the patient with chronic pain. In: Principles and practice of pain medicine, Warfield, CA, Bajwa, ZH (Eds), McGrawHill, USA, 2004: p.55-9.

13. Headache classification subcommittee of the International Headache Society. The International Classification of Headache Disorders: 2nd edition. Cephalalgia 2004; 24 Suppl. 1: S9.

14. Elias J, Kuniyoshi R, Carloni WV. Glossopharyngeal neuralgia associated with cardiac syncope. Arq Bras Cardiol. 2002; 78: 510-15.

15. Soh KB. The glossopharyngeal nerve, glossopharyngeal neuralgia and the Eagle's syndrome--current concepts and management. Singapore Med J. 1999; 40: 659-65.

16. Laha RK, Jannetta PJ. Glossopharyngeal neuralgia. J Neurosurg. 1977; 47: 316-22.

17. Patel A, Kassam A, Horowitz M, Chang YF. Microvascular decompression in the management of glossopharyngeal neuralgia: analysis of 217 cases. Neurosurgery, 2002; 50: 705-9.

18. Bruyn GW. Superior laryngeal neuralgia. Cephalalgia. 1983; 3: 235-9.

19. Watson P, Evans R. Cluster-tic syndrome. Headache, 1985; 25: 123-8.

20. Mulleners WM, Verhagen WI. Cluster-tic syndrome. Neurology, 1996; 47: 302-6.

21. Jaeger B, Singer E, Kroening R. Reflex sympathetic dystrophy of the face. Report of two cases and a review of the literature. Arch Neurol. 1986; 43: 693-8.

\section{Additional Information}

Disclosures: Authors report no conflict of interest.

Ethical Review Board Approval: The study was conformed to the ethical review board requirements.

Human Subjects: Consent was obtained by all patients/ participants in this study.

Conflicts of Interest:

In compliance with the ICMJE uniform disclosure form, all authors declare the following:

Financial Relationships: All authors have declared that they have no financial relationships at present or within the previous three years with any organizations that might have an interest in the submitted work.

Other Relationships: All authors have declared that there are no other relationships or activities that could appear to have influenced the submitted work.

Address for Correspondence:

Dr. Muhammad Hassan Raza

Punjab Institute of Neurosciences, Lahore

Email:Mhraza512@hotmail.com 


\begin{tabular}{|c|c|c|c|}
\hline \multicolumn{4}{|c|}{ AUTHORSHIP AND CONTRIBUTION DECLARATION } \\
\hline Sr.\# & Author's Full Name & Intellectual/Contribution to Paper in Terms of: & \\
\hline 1. & $\begin{array}{l}\text { Muhammad Hassan Raza } \\
\text { (Main/Principal Author). }\end{array}$ & $\begin{array}{l}\text { 1. Proposed topics and Basic Study Design, } \\
\text { methodology. }\end{array}$ & ure by the \\
\hline 2. & $\begin{array}{l}\text { Adeeb-ul-Hassan } \\
\text { (2nd Author) }\end{array}$ & 2. Data collection and calculations & author(s) \\
\hline 3. & $\begin{array}{l}\text { Omair Afzal Ali } \\
\text { (3rd Author) }\end{array}$ & 3. Analysis of data and interpretation of results etc. & \\
\hline 4. & $\begin{array}{l}\text { Khalid Mahmood } \\
\text { (4th Author) }\end{array}$ & 4. Literature review and manuscript writing & \\
\hline
\end{tabular}

Date of Submission: 20-10-2019

Date of Revision: 04-12-2019

Date of Online Publishing: 25-12-2019

Date of Print: 31-12-2019 